This is an electronic reprint of the original article. This reprint may differ from the original in pagination and typographic detail.

Please cite the original version: J. Ojasalo \& J. Kähäri (2018) OPPORTUNITIES OF COLLABORATIVE INNOVATION IN THE PUBLIC SECTOR: EMPIRICAL FINDINGS FROM THE PRIVATE SECTOR PERSPECTIVE, INTED2018 Proceedings, pp. 97729777.

doi: 10.21125/inted.2018.2453 


\title{
OPPORTUNITIES OF COLLABORATIVE INNOVATION IN THE PUBLIC SECTOR: EMPIRICAL FINDINGS FROM THE PRIVATE SECTOR PERSPECTIVE
}

\author{
Jukka Ojasalo, Jaakko Kähäri \\ Laurea University of Applied Sciences (FINLAND)
}

\begin{abstract}
The purpose of this paper is to increase knowledge of opportunities of collaborative innovation in the public sector from the private sector perspective. Collaborative innovation in the public sector means opening the innovation process up to multiple actors such as private and third sector organizations and citizens instead of keeping it within the boundaries of a particular governmental organization. The knowledge of collaborative innovation in the public sector is scarce so far. Empirically based research knowledge of the opportunities from the private sector perspective is in its infancy, in particular. The present study addresses this knowledge gap. It is based on empirical material collected from 20 private sector informants involved in collaborative innovation in the public sector. As the result, it identifies four main opportunities of collaborative innovation in the public sector and explains them. They are improved quality of solutions purchased by cities; positive financial impact for SMEs; new resources, contacts, and opportunities; as well as positive public image and social innovation. The results of this study have a clear practical implications particularly to urban policy makers and developers, companies and third sector organization collaborating with cities, as well as educators in the field of innovation and urban development.
\end{abstract}

Keywords: Collaborative innovation, Public sector innovation, Open innovation, PPP public private partnership, Smart City.

\section{INTRODUCTION}

The public sector plays an important role in generating innovations to tackle today's emergent and persistent challenges, for example the unstable global economy, climate change, and crime. Contemporary societies are becoming increasingly dynamic and complex in nature and the demands for public sector innovation are ever-growing. Furthermore, many governments are facing additional pressure to produce cost-effective solutions due to budget constraints caused by the financial crisis. Indeed, innovation in the public sector has become a topical subject of interest and is climbing towards the top in many governmental agendas. Even though the public sector has produced numerous celebrated innovations, it is argued and widely acknowledged that standard government solutions and the traditional ways of innovating in the public sector will not suffice in the face of the new emerging challenges and the citizens' rising expectations for public services [1,2,3,4].

The discussion on the public sector is often filled with strong preconceptions and stereotypes. Many attempts at explaining the public sector's shortcomings and figuring out how to improve public sector activities such as innovating are based on the assumption that governmental organizations are being outperformed by their private sector counterparts in various functions. Hence, comparing the public and private sectors in e.g. organizational, cultural, and strategic aspects has become an essential part of the literature on the public sector and a burgeoning field of study in its own right $[5,4,1,6]$. While it is fairly safe to assume that some of the stereotypes associated with the public sector are true, at least to a certain extent, there are also opinions and research suggesting that that the differences may not always be as prominent as one might think. Some organization and management theorists have even argued that the public-private distinction is unnecessary and that generally there are more similarities than differences between the sectors $[7,8,9]$.

The public administration has an important role in boosting innovation in the economy and at the same time, it should trigger innovation itself in the public organisations in order to increase productivity, to improve efficiency, to enhance the creation of public value and thus to meet the society challenges [10].

This paper increases knowledge of opportunities of collaborative innovation in the public sector from the private sector perspective. First, it reviews the existing research literature on collaborative 
innovation in the public sector. Then, it explains the empirical methods of the current research. After that, it describes the opportunities of collaborative innovation in the public sector identified in our study from the private sector perspective. Then, it draws the final conclusions.

\section{COLLABORATIVE INNOVATIO IN THE PUBLIC SECTOR}

Various reasons for the public sector's inability to respond to its innovation demands have been presented in the literature on public sector innovation. The public sector is considered highly bureaucratic by many and often associated with characteristics such as red tape, inertia, and topdown hierarchy $[3,4]$. The bureaucratic nature of most governmental organizations has been identified as one of the primary limiting factors to innovation within the public sector. Bommert [1] argues that bureaucratic governmental organizations tend not to take full advantage of all the innovation resources that exist at various levels within the organization and outside its borders as the innovation efforts primarily reside at the top of the organizational hierarchy - this results in reduced quality and quantity of the generation, implementation, and diffusion of new ideas. Furthermore, a risk-averse organizational culture and poor skills in risk and change management are common in the public sector and considered barriers to innovation [7]. In their empirical study on collaborative innovation in cities, Ojasalo \& Kauppinen [11] discovered that cities' organizations often lack systematic tools for cultivating innovation. They (ibid.) found out that city officials and employees are not blind to the need to foster innovation and are actually frequently identifying problems that have potential to turn into innovations when solved, but there seems to be a lack of methods and systematic approaches to take the innovation process to the next step which results in missed opportunities.

Collaborative innovation has emerged as a potential new way to help the public sector meet its innovation needs. Collaborative innovation in the public sector is based on the idea of opening the innovation process up to multiple actors such as private and third sector organizations and citizens as opposed to keeping it closed i.e. strictly within the boundaries of any particular governmental organization. The involvement of external actors in the innovation cycle increases the amount of both intangible and tangible innovation assets the public sector has at its disposal. In fact, the availability of the right kind of assets and matching them with problems are key in collaborative innovation and take priority over formal rules and roles of bureaucratic organizations [1].

The idea of collaborating with external actors is not particularly new in the public sector and the early examples can be dated back to the Roman imperial period, whereas more recent examples include e.g. various networked approaches to governance in which the utilization of assets across organizational boundaries is being emphasized. Opening processes and systems up to external actors with innovation-specific goals in mind has its origins in the private sector $[1,2]$. For example, Chesbrough [12] has presented the concept of Open Innovation that can be considered the polar opposite of the traditional approach in which innovations are generated through companies' internal research and development activities. Open Innovation is based on the idea that companies should utilize both internal and external ideas and paths to market in their quest to advance their technology and create value.

Collaboration has the potential to enable synergies in which the public sector together with various external actors can produce greater results and achieve more than what the sum of their individual efforts would be [2]. According to Bommert [1], collaborative innovation is a suitable approach for the public sector as it helps overcome the organizational and cultural barriers that restrict innovation in the public sector. Furthermore, the collaborative approach to innovation is beneficial for the generation, selection, implementation, and diffusion of ideas. Sørensen \& Torfing [4] present similar arguments and also note that the collaborative approach helps in identifying problems and challenges as well as assessing risks and benefits as it enables a broader perspective than innovating in-house.

Collaborative efforts between government and external actors are not free from challenges. The sharing of discretion between the parties involved can cause certain managerial difficulties as there is no fixed rule that determines how discretion should be dealt with. If the decision making of any particular effort is completely one-sided, it cannot be called a collaboration but rather a contract. However, finding out how to deal out discretion requires careful thought and balancing [2]. Another potential challenge to collaborative innovation is that actors from different sectors may have differing or contradicting interests and ideas how to utilize and disseminate the results of the innovation activities. As Bienkowska et al. [13] found out in their study on public-private innovation in Sweden, it might be problematic to find a hybrid order in which the private and public sectors' ways of using research results are in a symbiosis that is mutually reinforcing in nature. Hennala et al. [14] 
researched multi-actor involvement in public sector innovation processes and came to the conclusion that it can be challenging to create and maintain collaborative innovation processes that are perceived as equally beneficial to all par-ties involved.

Collaborative innovation is also a hot topic in the Smart City discussion and Erkkilä [15] considers the potential for collaboration a key element of a smart city. A connection between smart cities and collaborative innovation can also be identified in the social inclusion aspects of Smart Cities programs. According to Ojasalo \& Kauppinen [11], urban innovation is at the core of the Smart City concept and can benefit greatly from collaborative approaches. The perceived benefits are numerous and they (ibid.) have organized them into four categories as follows:

- Novel services/products/solutions

- Economic gains

- Urban and regional development

- Systemic improvements and process improvements

\section{METHOD}

This paper emerges from a 2-year research project on open innovation platforms in Smart Cities. The project addressed several objectives. The research method is qualitative and based on data from indepth interviews and co-creative workshops [16].The overall data of the research project include 65 indepth interviews from the following countries: Finland, Spain, Netherlands, China, Italy, Denmark, USA and Australia. The interviews were audio recorded and transcribed for later analysis. The interviewees also had a chance to make drawings during the interviews. The drawings were photographed, collected, and interpreted in the analysis. The informants represented public, private and $3^{\text {rd }}$ sector, as well as innovation platforms and research institutions.

The informants were selected based on their experience or expertise in innovation in the cities, public procurement, Living Labs, or other type of innovation intermediaries in the city context. The interviewees include persons from the city government, private companies, 3rd sector organizations, innovation intermediaries, as well as research institutions. Interviewees selected from the city government had experience or expertise in innovation, urban development, and collaboration with private/3rd sector organizations. Interviewees selected from the private sector had experience or expertise in collaboration with cities. Similarly, interviewees from 3rd sector had experience or expertise in collaboration with the cities. Interviewees from innovation intermediaries had experience or expertise in Living Labs or facilitation of collaborative innovation networks. Researchers interviewed were academics who have examined innovation intermediaries or urban development.

Interviews took around 1-3 hours. In addition to in-depth interviews, the data of this paper include material from 4 co-creative workshop addressing innovation collaboration between cities and external actors. The data of the workshops include the transcriptions of selected parts of the workshops, notes, photos on written and drawn material during the workshops, as well as written summaries of the main conclusions of the workshops.

From these 65 interviews the 20 private sector interviews represented the private sector and they were analysed in research reported in this paper. Thus, the results reported here are based on analysing the data from 20 informants representing the private sector.

The data were analyzed by open coding and selective coding, in terms of the grounded theory method [17]. "Open coding" or initial coding is described by Glaser [ibid., p. 56] as follows: "The goal of the analyst is to generate an emergent set of categories and their properties which fit, work and are relevant for integrating into a theory". "Selective coding" on the other hand, means that: "..analysis is guided by the core variable. Selective coding significantly delimits his [i.e. the analyst's] work from open coding, while he sees his focus within the total context he developed during the open coding". Thus, the effort moves from the general to the focused. The purpose of the "open coding" or initial coding in this study was in discovering a potential initial solution to be proposed for the existing knowledge gap, in other words, how to connect a city government and external actors for innovation collaboration. We identified a potential to propose an open innovation platform which contains an intermediary round table as a key element. With this initial idea or interpretation in mid the focus shifted to "selective coding". This included finding empirical clues from the material in hand which help in proposing the nature and structure of such innovation platform. As the result, we come up with a proposal of a model described in the next section (ibid.). 


\section{EMPIRICAL FINDINGS}

Next, we describe the findings on opportunities of collaborative innovation in the public identified in our study. These findings emerged from empirical research conducted among private sector actors involved in such collaboration. The results were presented in Kähäri 2017 [18]. They represent the private sector perspective to collaborative innovation in the public sector. The main opportunities identified from the private sector perspective are

- Improved quality of solutions purchased by cities

- Positive financial impact for SMEs

- New resources, contacts, and opportunities

- Positive public image and social innovation

\subsection{Improved Quality of Solutions Purchased by Cities}

Opening up the innovation projects and collaboration between cities and private sector companies holds potential to increase the amount of competition which is considered to have a positive effect on the quality of work. The idea is that as competition increases, qualitative metrics become more important as ranking suppliers based on price alone is not sufficient. Open and honest communication pertaining to collaborative innovation projects is also considered a quality-increasing elements as it enables better match-making - it helps the cities find the most suitable suppliers to fulfil their needs and it also helps the suppliers to realistically evaluate whether they have the right kind of solution for a particular project.

Another quality-related aspect that was identified in the data is that the possibility for cities to buy small solution packages from a wide pool of suppliers could potentially improve the quality of the solutions they are paying for. Splitting the purchases into smaller parts would enable more SMEs to participate in bidding which would increase competition. While taking such an approach may seem costly in the short-term, it is perceived to increase the quality of work and bring savings in the longterm as less damage control is required to fix problems arising from poorly rendered services.

\subsection{Positive Financial Impact for SMEs}

The buying power of a city is significant from an SME's point of view and becoming a supplier for a city can have a substantial financial impact on an SME's business. What may seem like a small project from a city's standpoint can be very important to a small supplier. Therefore, lowering the threshold for SMEs to become cities' suppliers has potential to affect a city's business environment in a positive way by supporting the companies in the area with new business opportunities.

Expanding the possibilities for SMEs to form alliances in order to become suppliers for cities as joint efforts is also regarded as a potential way to work in a more cost-effective manner, especially from the SMEs' point of view. Forming alliances allows the member companies to split costs and resources pertaining to participating in bidding for cities' projects.

\subsection{New Resources, Contacts, and Opportunities}

The data suggest that companies in the private sector see great potential in working on collaborative innovation projects with cities and other companies. Working on cities' challenges with new people and new customers can offer valuable insight on what is happening in the world and thus help identify new business opportunities and come up with new solutions. Based on the data, it seems that currently there is room to include more companies in cities' collaborative innovation projects and that it is indeed possible to achieve win-win situations in which no party needs to feel like the increased pool of suppliers is a threat to their existing business.

Collaborative innovation work with cities is also perceived to increase the possibilities to disseminate ideas across the borders of an individual city and thus create new business opportunities. Private sector companies seem to appreciate the idea that teaming up with a city as well as other companies. The other companies offer useful and increased resources. Also, this spreads out the word about successful projects and reach new customers such as other cities. In other words, collaborative innovation holds potential for companies to increase and widen the impact of their work which benefits not only the companies in terms of new business opportunities but also their customers in terms of better access to new solutions. The improved impact of collaborative innovation is also considered 
beneficial because it helps eliminate re-inventing the wheel as long as the results are scalable and openly disseminated.

The perception seems to be that forming alliances and consortia is currently a feasible way for companies, especially small and medium-sized ones, to get involved in collaborative innovation projects with cities. The current procurement policies of cities as well as the related national laws already allow for smaller companies to join forces in order to become eligible to bid. The data suggest that companies appreciate the fact that such possibilities exist and see great potential in them. Even though the current legislation on public procurement was largely considered a challenge to collaborative innovation, the data revealed an interesting notion in that some companies also see the new legislation as an enabling factor as pertains to the various possibilities to team up and become a city's supplier as part of an alliance.

\subsection{Positive Public Image and Social Innovation}

Collaborative innovation work also holds potential to help cities as well as the other parties involved building a positive public image through new innovations and successful projects. In addition to improving a city's image in the eyes of the citizens, successful collaborative innovation is likely to attract positive attention from other cities, companies, etc. Smart Cities programs and the work done in them tends to be recognized worldwide which is considered to help build not only the public image of a particular city, but rather the whole country in which the city is located.

Social innovation is also considered an important element of collaborative innovation work, especially the kind that involves citizens in the process. For example, if a collaborative innovation project focuses on a particular area of the city, the citizens may become an essential part of the process. By participating as end-users and interacting with each other, the citizens help to build a new social dimension of innovation that is important in Smart City programs.

\section{CONCLUSIONS}

The purpose of this paper was to increase knowledge of opportunities of collaborative innovation in the public sector from the private sector perspective. The empirically based knowledge of this area is very limited so far, and there was a clear need for this study. The empirical research was based on empirical material collected from 20 private sector informants involved in collaborative innovation in the public sector. As the result, our study contributed to the literature by identifiyng four main opportunities and explaining them. They were improved quality of solutions purchased by cities; positive financial impact for SMEs; new resources, contacts, and opportunities; as well as positive public image and social innovation.

The following opportunities for further research emerged from our study. Firstly, a comparative study on the differences between private and public sector perspectives to collaborative innovation is needed. This would help orchestrating the innovation collaboration between the private and public sector actors. Secondly, the role and opportunities of digitalization in the collaborative innovation in the public sector requires more investigation. Thirdly, more knowledge is needed of how different actors in the private sector perceive the collaborative innovation in the public sector, for example corporations vs. SMEs/startups, service vs. manufacturing industries, and international vs. local companies.

\section{REFERENCES}

[1] B. Bommert, "Collaborative Innovation in the Public Sector", International Public Management Review, vol. 11, no. pp. 1, 15-33, 2010.

[2] J. Donahue and R. Zeckhauser, R., "Collaborative Governance: Private Roles for Public Goals", in Turbulent Times. New Jersey, United States: Princeton University Press, 2011.

[3] E. Sørensen and J. Torfing, "Enhacing collaborative Innovation in the Public Sector", Administration and Society, vol. 43, no. 8, pp. 842-868, 2011.

[4] E. Sørensen and Torfing, J., "Introduction: Collaborative Innovation in the Public Sector", The Innovation Journal, vol. 17, no. 1, pp. 1-14, 2012. 
[5] H. Rainey and B. Bozeman, "Comparing Public and Private Organizations: Empirical Research and the Power of the A Priori", Journal of Public Administration Research \& Theory, vol. 10, no. 2, pp. 447-469, 2000.

[6] T. Halvorsen, T., "On Innovation in the Public Sector", in Halvorsen, T., Hauknes, J., Miles, I. \& Rannveig, R. (eds.) On the Differences Between Public and Private Sector Innovation. Publin Report No. D9. Oslo, Norway: Nifu Step. pp. 2-21, 2005.

[7] D. Albury, D., "Fostering Innovation in Public Services," Public Money \& Management, vol. 25, no. 1, pp. 51-56, 2005.

[8] H. Rainey and Y. Chun, Y., "Public and Private Management Compared,". in Ferlie, E., Lynn, L. \& Pollitt, C. (eds.) The Oxford Handbook of Public Management, Oxford, United Kingdom: Oxford University Press, p. 71-105, 2009.

[9] R. Lachman, R., "Public and Private Sector Differences: CEO's Perceptions of their Role Environments", Academy of Management Journal, vol. 28, no. 3, pp. 671-680, 1985.

[10] A. Matei and C. Savulescu, C., "Enhancing the capacity for innovation of public administration. An exploratory study on e-Governance, ICT, knowledge management in Romania", Theoretical and Applied Economics, vol. XXI, no. 11, pp. 7-26, 2014.

[11] J. Ojasalo and H. Kauppinen, "Collaborative Innovation with External Actors: An Empirical Study on Open Innovation Platforms in Smart Cities", Technology Innovation Management Review, vol. 6, no. 12, pp. 49-60, 2016.

[12] H. Chesbrough, H., "Open Innovation: A New Paradigm for Understanding Industrial Innovation", in Chesbrough, H., Vanhaverbeke, W. \& West, J. (eds.) Open Innovation: Researching a New Paradigm, New York, United States: Oxford University Press, pp. 1-12, 2006.

[13] D. Bienkowska, K. Larsen and S. Sörlin, S., "Public-Private Innovation: Mediating Roles and ICT Niches of Industrial Research Institutes", Innovation: Organization \& Management, vol. 12, no. 2, pp. 201-216, 2010.

[14] L. Hennala, S. Parjanen and T. Uotila,, "Challenges of Multi-Actor Involvement in the Public Sector Front-End Innovation Processes", European Journal of Innovation Management, vol. 14, no. 3, pp. 364-387, 2010.

[15] K. Erkkilä, K., "Espoo is a Smart City through Collaboration", Interdisciplinary Studies Journal, vol. 3, no. 4, pp. 218-226, 2014.

[16] E. Gummesson, E., Qualitative Methods in Management Research, 2nd ed., Sage Publications, California, 2000.

[17] B.G. Glaser, Theoretical Sensitivity, The Sociological Press, California, 1978.

J. Kähäri, A Private Sector Perspective on Enhancing Collaborative Innovation in Cities Empirical Results from a Smart City Research Project, Laurea University of Applied Sciences, Espoo, 2017. 